\title{
NEAR-INFRARED SPECTROSCOPY AND HIDDEN GRAPHICS APPLIED IN PRINTING SECURITY DOCUMENTS IN THE OFFSET TECHNIQUE
}

\author{
Vilko ŽILJAK, Jana ŽILJAK GRŠIĆ, Denis JUREČIĆ, Tonči JELIČIĆ
}

\begin{abstract}
The method of mixing pigments for the printing technology is expanded with the addition of dual states in security graphics. Near-infrared spectroscopy of colorants used in the offset technique has brought about the concept of targeted design by a selective use of colorants that are visible in the visible region of the electromagnetic spectrum. High-security documents have been observed in the NIR light based on twin colorants which are differentiated according to their NIR absorption in the range from 800 to $1000 \mathrm{~nm}$. New procedures have been developed based on the innovative creation of documents with hidden information. Two graphics are combined with mutating screen elements. A mathematical definition of the new printing screen and an algorithm in PostScript are given. The designer plans and creates graphics, which originate from the twin colorants, by using the INFRAREDESIGN® method. The dual design was investigated using visual and infrared cameras for the forensic area. The components of colorants are determined by the spectroscopy of light absorption with filters in the visual and NIR spectrum.
\end{abstract}

Keywords: hidden graphics; near-infrared spectroscopy; offset printing; security screen; twin colorants

\section{INTRODUCTION}

Instrumental observation of near-infrared graphics has initiated the expansion of security printing into the conventional printing practice. Our research into protected coloring is published with applications in digital printing with toners, flexographic printing and with the introduction of image duality in two light spectra [1]. In this paper, the application of twin colorants for the offset technique is published. The twins of colorants are prepared with the corresponding offset colorants from the "scale" - that is, with the set of the $\mathrm{C}, \mathrm{M}, \mathrm{Y}, \mathrm{K}$ components for process printing. The INFRAREDESIGN ${ }^{\circledR}$ technology is prepared at high circulation in the newspaper press [2]. The idea of "twin colorants" is partly explained in the work on the application of the inkjet print on textiles for dresses in the clothing industry [3]. This article is based on the INFRAREDESIGN ${ }^{\circledR}$ theory, which gives principles for combining two images [4]. The construction of dual cameras (ZRGB) is described in the article by Ivan Rajković et al. [5], with application in film set design. Cameras are used as an instrument for determining light absorption on pigments and colorants in the industry [6].
This article requires explanations for the abbreviations used in the application of IRD.

The spectrum of the naked eye - red, green, blue (RGB) - is marked as V (visual). Absorption in the segment of the NIR spectrum at $1000 \mathrm{~nm}$ is marked as Z. The same abbreviations are used for the corresponding photographic cameras. The hidden image at $1000 \mathrm{~nm}$ is called the $\mathrm{Z}$ image ( $\mathrm{Z}$ information). Colorants which do not absorb $\mathrm{Z}$ radiation are called V colorants. The observation of colorants through the system of "twins of colors and colorants" [7] has been introduced. The different groups of twin colorants are recognized by the ZRGB camera, which determines and assigns numerical values of the light absorption of colored material [8].

\section{RECIPES FOR TWIN COLORS FOR THE OFFSET TECHNIQUE}

The numerical values of the recipes for the $\mathrm{C}, \mathrm{M}, \mathrm{Y}$ and $\mathrm{K}$ process colorant components are given. The colorants chosen for raster printing are the same as the colors in the security document (Tab. 1). Images of twin colorants at 1000 $\mathrm{nm}$ were added using a dual ZRGB camera [8].

Table 1 The recipes of twin colorants with the $C, M, Y, K$ dyes

\begin{tabular}{|l|c|c|c|c|}
\hline \multicolumn{1}{|c|}{ Colors } & $\mathrm{RGB}\left(2^{8}\right)$ & $\mathrm{C}, \mathrm{M}, \mathrm{Y}, \mathrm{K} \%$ & $\mathrm{C}, \mathrm{M}, \mathrm{Y}, \mathrm{K} \%$ & $L^{*} a^{*} b$ \\
\hline 1 Hidden letters, Z & $102,82,78$ & $65,69,67,0$ & $36,47,40,42$ & $37,11,7$ \\
\hline 2 Dark thin line; V, Z & $46,0,0$ & $89,97,99,0$ & $38,85,78,65$ & $0,46,15$ \\
\hline 3 Blue-green surface, V & $57,67,106$ & $89,71,42,0$ & $71,49,9,40$ & $28,4,-27$ \\
\hline 4 Gray color, V & $129,134,151$ & $55,41,27,0$ & $27,13,0,40$ & $26,0,-11$ \\
\hline
\end{tabular}

Twin colorants were photographed with filters at 400 , $470,570,610 \mathrm{~nm}$ and in the visible spectrum. Light absorption was measured by using the Projectina forensic camera [9] for the visible (V - RGB) and near-infrared (NIR $-\mathrm{Z})$ spectrum. The record of each photograph was analyzed as the remaining light reflection after blocking the designated wavelengths of light. At the same time, this is the prepress that can prove the authenticity of the document in the case of forgery. Textual information can be found on the document: "SECURITIES CONFIRMATION". Hidden information is programmed as vector graphics enveloped in the dense lines of different sets of twin colorants. Since the design is applied in two light spectra, it has two images which are observed separately with ZRGB cameras. Images V (visible) and Z 
(NIR spectrum) present an example of security graphics with mutual concealment if they are printed next to each other and partially nested in each other. Although the original design was created as vector graphics, the prepress is a highresolution pixel graphic.

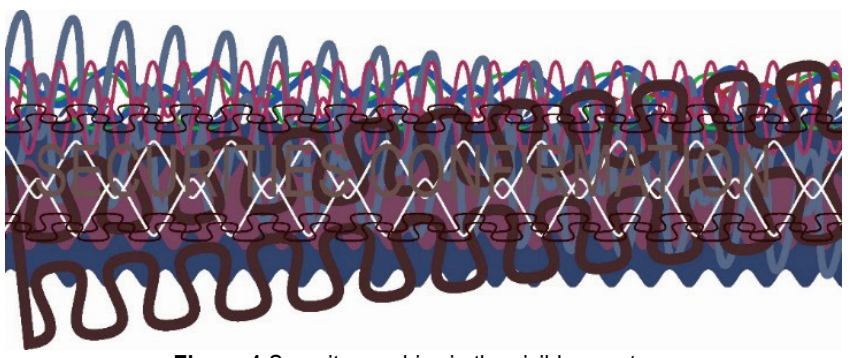

Figure 1 Security graphics in the visible spectrum

The transition of the color twins and change in the light absorption from the $\mathrm{V}$ to $\mathrm{Z}$ state in dual presentation are shown as a video animation. Fig. 2 shows security graphics in the blockade at $700 \mathrm{~nm}$. Some colorants already disappear in the visible spectrum, while others are visible up to $750 \mathrm{~nm}$. After $800 \mathrm{~nm}$, only the information on the absorption of the near-infrared spectrum remains.
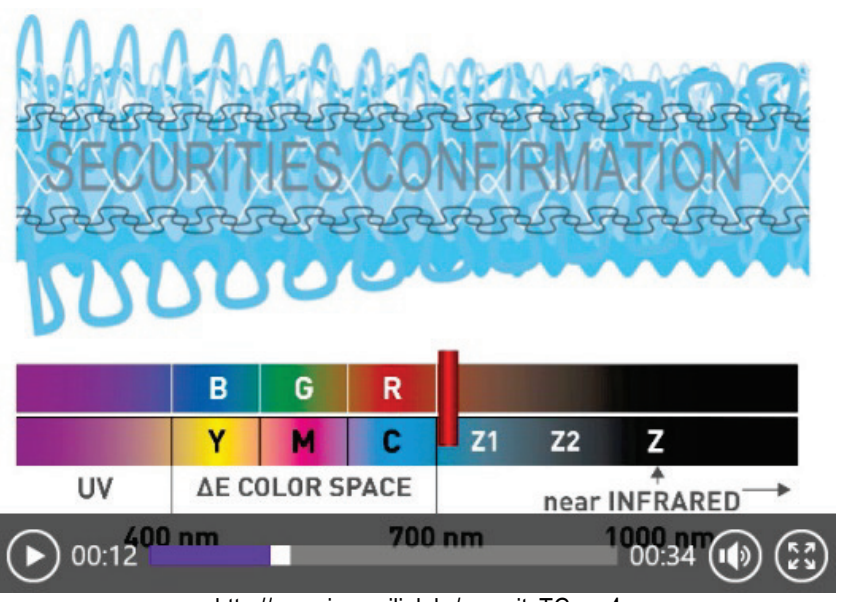

http://www.jana.ziljak.hr/securityTG.mp4

Figure 2 Twin dyes in blockages from the visible to the NIR spectrum up to 1000 $\mathrm{nm}$

\section{SCREENING FOR SECURITY PRINT WITH THE MUTATING RASTER FORM R87}

Individualized rasterization is used in design as an original solution. This is an introduction into security graphics with an emphasis on the stochastic choice of line screen coverage [10]. In this paper, the mutating screen form R87, which deforms and changes its appearance in print depending on the amount of colorant applied, is presented. After pixelization, raster color interpretation is introduced. With them, the recognition of color-coded twins that are nested is reduced.
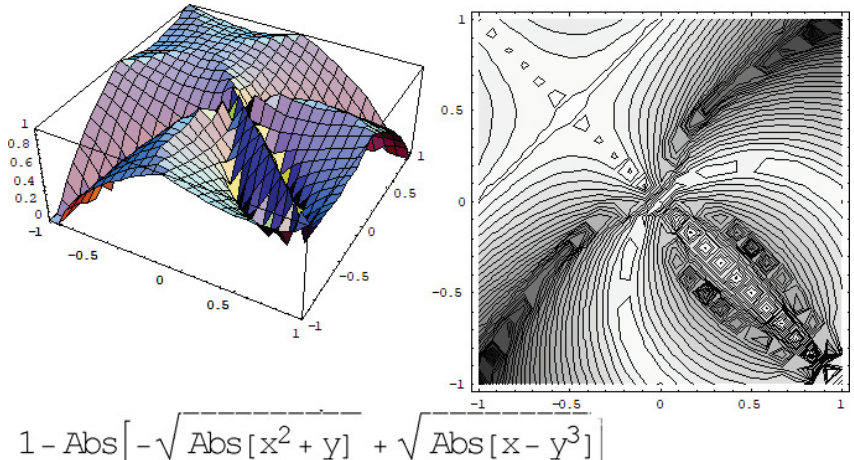

$1-\operatorname{Abs}\left[-\sqrt{\operatorname{Abs}\left[\mathrm{x}^{2}+\mathrm{y}\right]}+\sqrt{\operatorname{Abs}\left[\mathrm{x}-\mathrm{y}^{3}\right]}\right]$

Figure 3 The model of the screen form $R 87$ in $3 D / 2 D$ with the corresponding algorithm

Table 2 Algorithm (PostScript - GSview 5.0) of the activated three-screen shape:

15600 translate 4080 scale

/rounddot \{dup mul exch dup mul add 1 exch sub bind def

/propeler \{dup 2 index 3 exp sub abs sqrt 31 roll 3 exp add abs sqrt exch sub abs 1 exch sub $\}$ bind def

/R78 \{dup 2 index 3 exp sub abs sqrt 31 roll 2 exp add abs sqrt exch sub abs 1 exch sub $\}$ bind def

/lin 5 def /kut 0 def

lin kut \{rounddot\} bind setscreen 01.1 neg translate

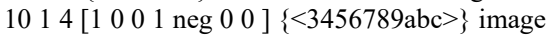

lin kut \{propeler\} bind setscreen 01.1 neg translate

1014 [1 1001 neg 00 0 $\{<3456789 \mathrm{abc}>\}$ image

lin kut $\{R 78\}$ bind setscreen 01.1 neg translate

$1014\left[\begin{array}{llllll}1 & 0 & 0 & 1 \text { neg } & 0 & 0\end{array}\right]\{<3456789 \mathrm{abc}>\}$ image

lin kut $\{R 78\}$ bind setscreen $01.1 \mathrm{neg}$ translate

1014 [1 001 neg 00 ] $\{<8394 \mathrm{c} 26 \mathrm{~b} 5 \mathrm{a}>\}$ image

Showpage
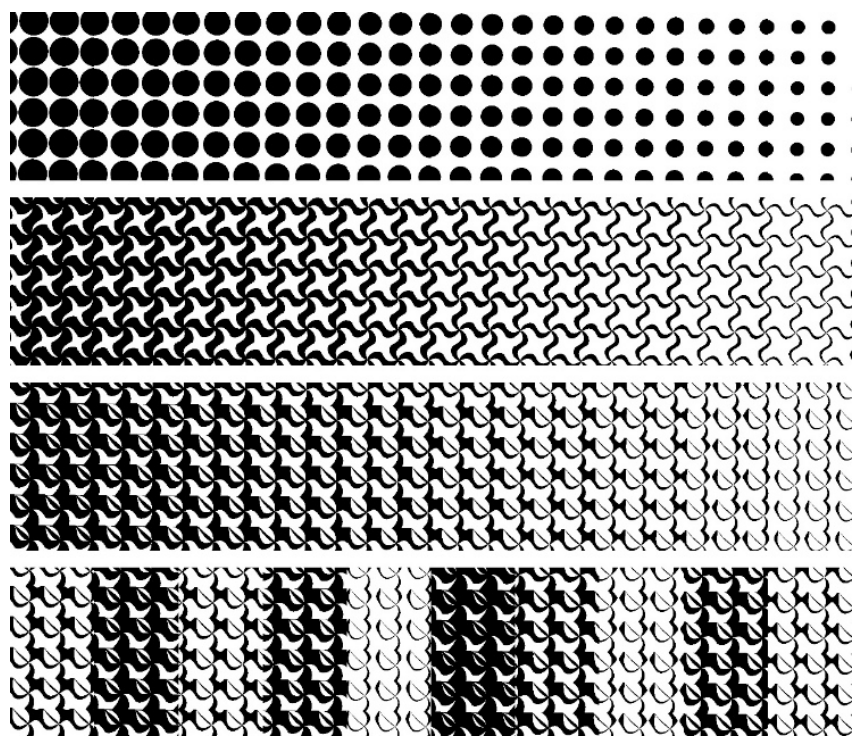

Figure 4 Macro-view (5 lines per inch) of the continuous screen/raster form:

round dot, propeller, R87, and 4 bit hexa schedule $<8394 c 26 b 5 a>R 87$

The first raster shape is a standard round dot applied in conventional printing. For security printing, we suggest new raster forms: "propeller" and R87. With the passage of time and the ageing of documents, the colorant values change. The IRD technique insists on minimizing the difference between the twins of colors in the visible spectrum. The $\Delta E$ numerical values are less than three, which is recommended for the 
mutual concealment of two graphics. The experimental work in the development of twin colorants has confirmed that mixing the $\mathrm{V}$ and $\mathrm{Z}$ twins of colorants in print depends on the geometrical shape of the raster element. Better solutions for hiding the $\mathrm{V}$ and $\mathrm{Z}$ images are achieved with mutating rasters from the "horn-shaped" series. The $\mathrm{Z}$ graphics printed next to the $\mathrm{V}$ graphics (with the same color) are less discernible if their contact surfaces are jagged. This was the motivation to create and apply the new raster form R87, resulting in an individual solution which raises the quality of print in security graphics.

\section{NIR SPECTROSCOPY OF TWIN COLORANTS FOR THE OFFSET PRINTING TECHNIQUE}

The equality of the twins of colorants in the visible spectrum is expressed through the $\Delta E$ value, for which several analytical solutions have been proposed [11]. The $\Delta Z$ value, which measures the difference of light absorption in the near-infrared spectrum [12], has been introduced into the IRD printing technique. There is no analytical solution for this value. The practices of photographing with ZRGB cameras and determining the difference of grayness on photographs with conventional programs for image processing are introduced. In this article, it is shown that the spectrum of light absorption for the twin colorants in the visible and near-infrared spectra is from 400 to $1000 \mathrm{~nm}$. Spectrograms are given for colorants from the examples of security print (Fig. 2), with an emphasis on the $Z$ value of the wavelength area at $900 \mathrm{~nm}$. Fig. 6 shows spectrograms of the twins of the gray and green color tone. Spectroscopy was performed from the print samples.

The dashed lines (V colorants) drop to zero after $800 \mathrm{~nm}$ in the NIR region. At a measurement above $900 \mathrm{~nm}$, the difference between the $\mathrm{V}$ and $\mathrm{Z}$ colorant twins is determined. Dyes with the $K$ content greater than $40 \%$ retain the $\Delta Z$ range that the $\mathrm{Z}$ camera will interpret as a dark area.

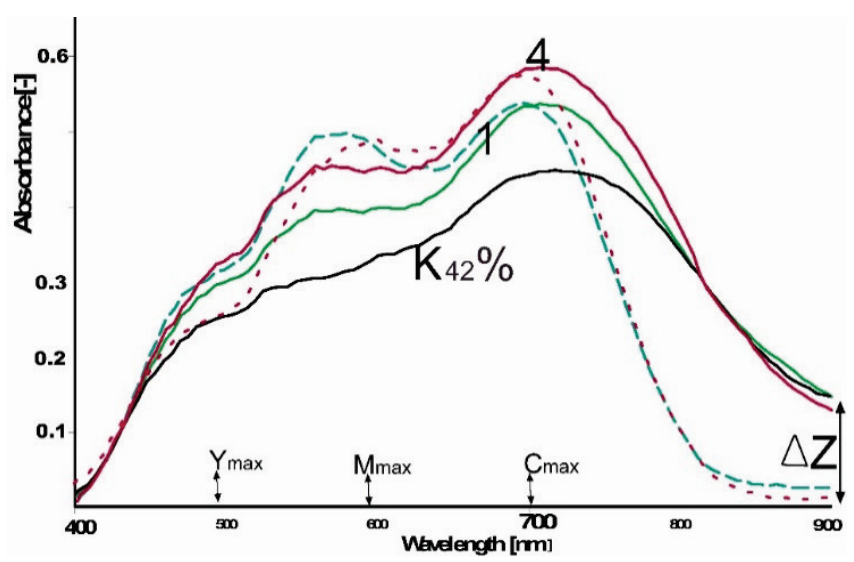

Figure 5 Spectrograms of the light absorption of colorants 1, 4 (Tab. 1)

The light absorption maxima are: yellow at $490 \mathrm{~nm}$, magenta at $590 \mathrm{~nm}$ and cyan at $700 \mathrm{~nm}$ [12]. The advantage of the spectral, graphical representation is explained by the twins' dyes No. 1. There are major discrepancies in the colors of the twins No. 1 in the magenta area. This is information on the necessary repair of the dye mix No. 1 . The difference in the absorption value in the magenta dominance (from $540 \mathrm{~nm}$ up to $650 \mathrm{~nm}-69 \% / 47 \%$ ) is too large. The difference in the magenta coverage in twins with $42 \% \mathrm{~K}$ is too small. In the next iteration of the trial print, either the magenta $\mathrm{V}$ dyes (solid line) will increase or the magenta content of the $\mathrm{Z}$ twin (dash line) will decrease. The line No. 2 (Fig. 6) is a thin dark line with a high proportion of carbon black dyes (65\%). That line will remain in the final $\mathrm{Z}$ image (video, Fig. 2)

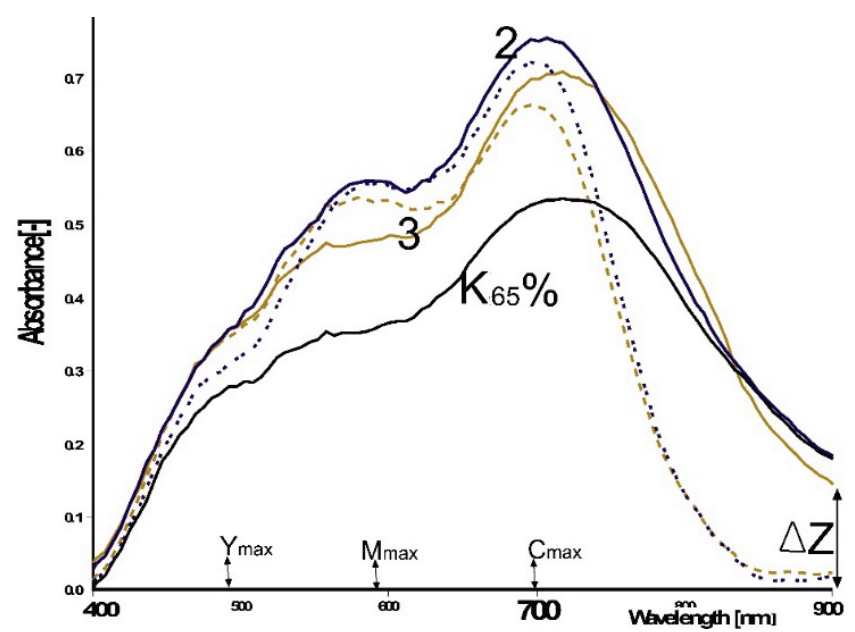

Figure 6 Spectrograms of the light absorption of the colorants 2, 3 (Tab. 1)

The parameters for the ratio of the $\mathrm{C}, \mathrm{M}, \mathrm{Y}, \mathrm{K}$ process components were determined in six iterations of print. The graphic representation of light absorption is the ideal method for proposing a new direction in adjusting the ratios of every CMYK component. Since process colorants are in their own domains, spectrograms of individual components as the final optimal solution are given in the article [12].

\section{DISCUSSION AND CONCLUSION}

In our work with security graphics, the colorant carbon black for the $\mathrm{Z}$ twin is given beforehand. Security graphics in our research use colorants with a strictly defined order: the NIR colorant has coverage of $40 \%$ and is determined in advance. All other parameters in the $\mathrm{V}$ and $\mathrm{Z}$ colorants are subordinate to this requirement for security print. The amounts of $\mathrm{C}, \mathrm{M}, \mathrm{Y}, \mathrm{K}$ colorants in $\mathrm{V}$ and $\mathrm{Z}$ are adjusted in order to minimize $\Delta E$. Such design of the relationship between the $\mathrm{V}$ and $\mathrm{Z}$ graphic is the beginning of developing contrast in the instrumental observation of the visible and hidden image. A larger amount of the carbon black colorant reduces the scope of the coloration of security graphics. We propose further experimentation with smaller values of the coverage of the component $\mathrm{K}$ in $\mathrm{Z}$ graphics.

$\mathrm{Z}$ graphic comes at the end of the graphic postpress for the four-color print, because vector graphics programs ignore it in the second, invisible order. Joining the lines, the overlay order is carefully worked out because the final graphic is interpreted as pixel graphics. Discarding information (second line "below") is a standard process in the digital transition from vector to pixel graphics. Let us emphasize: this is not 
about the transparency of dyes. Only, if press were released separately for each layer, printing with spot dyes would be possible. This is possible in offset, but the printing is significantly more expensive. A test print on a digital printer is not suitable for "print in layers".

Security graphics recognizes different process colorants based on their absorption of near-infrared radiation. Three colorants for standard offset printing - cyan, magenta and yellow - do not absorb light outside the visible spectrum. We plan to use them as components in graphics which are intended only for the visible spectrum without showing up in the near-infrared spectrum, but with set differences in the $\mathrm{V}$ and $\mathrm{Z}$ graphics. This proposition is the beginning of creating security graphics with two different levels of content, which are instrumentally separated by using ZRGB cameras.

IRD security graphics is sensitive to the quality of twin colorants and their sameness in the visible spectrum. We propose the introduction of raster elements with pointed forms. The mixing of colorants and the contact between the $\mathrm{V}$ and $\mathrm{Z}$ graphics is planned at the level of an irregular raster form. Such vibrating graphics have two advantages. Firstly, they are almost impossible to detect even with highresolution scanners. Scanners that are currently in use reduce all images to RGB records, which are then interpreted using the GCR (CMYK) procedure, destroying the principle of the IRD print in the process. Furthermore, the two graphics of $\mathrm{V}$ and $\mathrm{Z}$ are in contact; they have a different content of the same color at the same place. For the naked eye, the new raster elements (R87) reduce the gap, i.e. the possibility to recognize the boundary between the graphics $\mathrm{V}$ and $\mathrm{Z}$.

The planning of the quantities of individual components of process colorants is observed through the $\Delta \mathrm{E}$ and $\Delta \mathrm{Z}$ values. The amount of each CMYK component in twin colorants is determined through the spectrography of the mixture and the spectrography of each CMYK component separately. A final note: the new printing system of security graphics is based on the use only with the same colorants, which are used for conventional print.

\section{REFERENCES}

[1] Friščić, M., Agić, A., \& Žiljak Stanimirović, I. (2017). Visual and infrared graphic applied through dedicated halftoning for transparent polypropylene packaging. Tehnički vjesnik, 24(1), 225-230. https://doi.org/10.17559/TV-20151231105549

[2] Anayath, Rajendradrakumar \& Žiljak, V. (2011, Feb.). Invisible pics hit newspaper. RIND Survey, Chennal, India, Rs.40.00, 32(2), 4-6.

[3] Žiljak, V., Akalovic, J., \& Žiljak-Vujić, J. (2011). Upravljanje bojilima na koži u vizualnom i infracrvenom spektru. Tekstil : casopis za tekstilnu tehnologiju i konfekciju, (0492-5882), 60(8), 355-363.

[4] Žiljak, V., Pap, K., \& Žiljak, I. (2009). CMYKIR security graphics separation in the infrared area. Infrared Physics and Technology, 52(2-3), 62-69. https://doi.org/10.1016/j.infrared.2009.01.001

[5] Žiljak Vujić, J., Rajković, I., \& Žiljak Stanimirović, I. (2014). Simultano video snimanje u vizualnom i infracrvenom spektru proširene V/Z stvarnosti. Polytechnic \& Design, 2(1), 73-78.
[6] Rajković, I. \& Žiljak, V. (2018). Parallel Motion Images in Visual and Near Infrared Spectrum. Tehnički vjesnik, 25(4), 1004-1008. https://doi.org/10.17559/TV-20160610125726

[7] Žiljak, J., Jurečić, D., \& Žiljak, V. (2018). Packaging Design with Hidden near Infrared Colour Separation. Tehnički vjesnik, 25(3), 211-215. https://doi.org/10.17559/TV-20170705114921

[8] Žiljak, V., Pap, K., \& Žiljak-Stanimirović, I. (2011). Development of a Prototype for ZRGB Infraredesign Device. Tehnički vjesnik, 18(2), 153-159.

[9] Projectina Docucenter 4500, PAG B50 http://forensictechnology.com/projectina/ http://www.projectina.ch/cre8.upload/pdfs/UCM\%20LED\%2 0PIA-7000\%202011-e.pdf

[10] Žiljak Stanimirović, I., Anayath, Rajendra, \& Bogovic, T. (2010). The Infraredesign with Individualised Screening. Proceedins of $11^{\text {th }}$ International Design Conference, Design Graphics with security elements, Vol. 4, The Design Society, Dubrovnik, Croatia, 1863-1868.

[11] Glogar, M. I. \& Parac-Osterman, Đ. (2015). Achromatic Hues Matching in Graphic Printing. Acta graphica, 26(1-2), 36-45. https://hrcak.srce.hr/145334

[12] Žiljak Gršić, J. (2017). Near infrared spectroscopy in print technology. Polytechnic \& Design, 5(1), 32-36. https://doi.org/10.19279/TVZ.PD.2017-5-1-05-en

\author{
Authors' contacts: \\ Vilko ŽILJAK \\ (Corresponding author) \\ Faculty of Graphic Arts, University of Zagreb, \\ Getaldićeva 2, 10000 Zagreb, Croatia \\ vilko@ziljak.hr \\ Jana ŽILJAK GRŠIĆ \\ Zagreb University of Applied Sciences, \\ Vrbik 8, 10000 Zagreb, Croatia \\ jana@ziljak.hr \\ Denis JUREČIĆ \\ Faculty of Graphic Arts, University of Zagreb, \\ Getaldićeva 2, 10000 Zagreb, Croatia \\ denis.jurecic@grf.hr \\ Tonči JELIČIĆ \\ Hydrographic Institute of the Republic of Croatia, \\ Zrinsko-Frankopanska 161, 21000 Split, Croatia \\ tonci.jelicic@hhi.hr
}

